\title{
The Effects of Caffeinated Beverage Consumption on the Sleep Habits and Lifestyle of Medical Students in Public and Private Medical Universities in Karachi, Pakistan
}

Author 1: Maham Noor Afroz

noormaham10@gmail.com

+92 3312842736

Final year medical student, Jinnah Sindh Medical University.

Author 2: Ayesha Asghar (corresponding author)

ayeshasghar98@gmail.com

+92 3017349771

Final year medical student, Jinnah Sindh Medical University.

Author 3: Shaheera Kamal

sherrykm196@gmail.com

+923132714095

Final year medical student, Jinnah Sindh Medical University.

Author 4: Saneea Ishfaque

saneeaishfaque95@gmail.com

+923362054334

Final year medical student, Jinnah Sindh Medical University.

Author 5: Shueeta Chander Bhan

shweti.motlani@gmail.com

+92 3322148023

Final year medical student, Jinnah Sindh Medical University.

Author 6: Anum Kamal

anumkamal@rocketmail.com

+92 3333486979

Final year medical student, Jinnah Sindh Medical University.

Author 7: Hira tariq

Hiratariq14@hotmail.com

+923312337597

APPNA Institute of Public Health

Jinnah Sindh Medical University Rafiqui H.J Shaheed Road Karachi. 
Objectives: To determine the effects of caffeine consumption on the sleep habits and lifestyle of medical students.

Methods: A cross-sectional study was conducted at Jinnah Sindh Medical University (JSMU) and Hamdard College of Medicine. On 422 undergraduate students aged 18-25 years, through random sampling. The duration of the study was from January 2019 to June 2019. The data was collected through self-administered questionnaire which included data regarding sleep habits and lifestyle of medical students.

Results: Majority (81.6\%) of the students consumed caffeine while only (18.4\%) did not. One third of the participants $(31.8 \%)$ reported caffeine consumption increased their academic performance and $(57.3 \%)$ reported that it does not. More than half of the participants $(63.3 \%)$ who consumed caffeine slept during class, whereas (47.2\%) never had difficulty in falling asleep during the night.

Conclusion: This research concluded that caffeine does have some role on sleep habits of medical students as they tend to have less sleep hours, experience day time dysfunction, average quality of sleep, and falling asleep during class. It has been concluded that caffeine has no effect on eating habits of medical students however, it does increase the screening time, keeping them active.

Keywords: caffeine, sleep habits, lifestyle, medical students, universities.

IRB: Approved by Institutional Review board, Jinnah Sindh Medical university.

\section{INTRODUCTION:}

Sleep is known to have a significant role in a person's body function, as it regulates hormone release and has effects on daytime functioning, cardiovascular activity, endocrine and nervous systems ${ }^{(1)}$. Sleep is physiologically significant for a sound mind and body. There are several adverse health conditions associated with poor sleep quality. The commonly experienced effects of sleep related problems are easy fatigability, daytime sleepiness and decreased ability to perform day tasks ${ }^{(4)}$. Poor sleep is associated with increased risk of hypertension, stroke, diabetes and increase in BMI among college students who are mostly young adults ${ }^{(4-5)}$.

Poor sleep quality is prevalent nowadays and is associated with cognitive decline, impaired health and reduced quality of life ${ }^{(6)}$. Poor sleep quality is associated with excessive daytime sleepiness, defined as having increased propensity to fall asleep unintentionally during daytime ${ }^{(7)}$. Universities going medical students are more likely to have poor sleep quality due to irregular daytime routines, exam periods, use of caffeinated drinks, and use of technologies like mobile phones or television late at night ${ }^{(8)}$.Majority of the students are suffering from various sleep problems with insomnia being very common. Other sleep related problems that the students suffer from are snoring, sleep apnea, sleep deprivation, sleep paralysis.

Most of the medical students are sleep deprived to compensate the hours of study ${ }^{(1)}$. Students rely on consumption of coffee/tea/beverages with caffeine to stay awake and fresh decreasing the desire to sleep. Excessive use of caffeinated beverages has been seen to be implicated in this process ${ }^{(2)}$. Sleep deprivation usually results in fatigue, loss of concentration, daytime sleepiness. Sleep is also affected by the exercise ${ }^{(3)}$. More than 120000 tons of caffeine is consumed per year In United States ${ }^{(9)}$. Caffeine is used by $80 \%$ of the world's population. Caffeine is a psychoactive drug that stimulates the central nervous system. 
The ergogenic properties of caffeine also supplement the performance of athletes in physical games. The adverse effects of caffeine are headache, palpitations, anxiety and insomnia. More serious adverse effects include vomiting and abdominal pain, hypokalemia, hallucinations, seizures, arrhythmias and even death (10). Caffeine dependence may develop among individuals who consume caffeine because of a need to counteract sleep inertia ${ }^{(1)}$. Along with sleep disruptive effects of caffeine it also enhances the performance of a medical student in academics ${ }^{(11)}$. The aim of the study is to determine the effects of caffeine consumption on the lifestyle and sleep habits of medical students of public and private medical universities in Karachi.

\section{MATERIAL \& METHODS}

A cross-sectional survey was conducted in 2019, at one public (Jinnah Sindh Medical University) and one private medical university (Hamdard University) after the approval of IRB. The sample size was calculated through OpenEpi proportion sample size calculator, based on a study according to which, prevalence of energy drinks among medical students in DMC was 39\% and in Aga Khan University was 51.9\%. Keeping the anticipated frequency of $50 \%$ for life style and sleep habits and using $95 \%$ confidence interval with bound of error of $5 \%$, sample size came out to be 384 . However, considering wasting of $10 \%$ for statistical convenience we recruited 422 subjects. The data was collected through random sampling. Students aged 1825 years, from first to final year MBBS studying in private and public medical universities were included. Students who were having any systemic diseases, taking any medication and females who were pregnant were excluded from the survey. The confidentiality and anonymity of the participants was strictly ensured. Informed consent was signed by all participants. Age, gender, year of education, physical activity, sleep habits were assessed using a standardized questionnaire. Lifestyle variables included are daily routine, total daily screen time, hobbies and physical activity level. Data will be analyzed using SPSS version 23. Mean and standard deviation were calculated for quantitative variables and frequency for categorical variables.

\section{RESULTS:}

Majority of the participants (79.4\%) were females and $(20.6 \%)$ were males. Nearly half were between 20-21 years old (44.3\%) while (30.6\%) were between $22-23$ years of age. About $(55.9 \%)$ belonged to public medical university and $(44.1 \%)$ belonged to private medical university. Majority lived with their families (86.7\%) while only a few resided in hostels (13.3\%). (Table: 1$)$

Majority $(88.6 \%)$ of the students consumed caffeine in any form while only $(11.4 \%)$ of the students didn't consume caffeine at all. Almost half (43.4\%) responded that they sleep between 11-1am followed by $(39.8 \%)$ by 1-3am during college nights. During weekend (42.7\%) sleep between 1-3am, however a significant low (4.3\%) were seen to sleep at between 9-11pm. The duration of sleep of nearly half of the participants $(46.9 \%)$ was less than 6 hours i.e. only $(1.4 \%)$ were sleeping more than 8 hours. $(28.9 \%)$ marked that they experienced daytime dysfunction once a week and $(28.7 \%)$ said twice a week. About half of the population (55.2\%) rated their sleep quality average, (16.6\%) stated that they find it difficult to fall asleep during weekdays while another $(16.6 \%)$ throughout the week.

On asking respondents how many times they wake up once they have fallen asleep, (33.9\%) marked 1-3 times. Almost half (49.1\%) found it hard to stay awake during university hours. About $1 / 3$ i.e. $(63.3 \%)$ population have fallen asleep during class while $(47.2 \%)$ never had difficulty in falling asleep during night. (Table. 2) 


\begin{tabular}{|c|c|}
\hline $\begin{array}{l}\text { Table 1: Socio } \\
\text { characteristics of the } \\
(n=422)\end{array}$ & $\begin{array}{l}\text { demographic } \\
\text { study participants }\end{array}$ \\
\hline Variables & $\% / n$ \\
\hline GENDER & \\
\hline Female & $79.4 \%(335)$ \\
\hline Male & $20.6 \%(87)$ \\
\hline $\mathrm{AGE}$ & \\
\hline $18-19$ & $22 \%(93)$ \\
\hline $20-21$ & $44.3 \%(187)$ \\
\hline $22-23$ & $30.6 \%(129)$ \\
\hline $24-25$ & $3.1 \%(13)$ \\
\hline University & \\
\hline $\begin{array}{ll}\text { Public } & \text { medical } \\
\text { university } & \end{array}$ & $55.9 \%(236)$ \\
\hline $\begin{array}{l}\text { Private } \\
\text { University }\end{array}$ & $44.1 \%(186)$ \\
\hline Year of education & \\
\hline $1^{\text {st }}$ year & $21.3 \%(90)$ \\
\hline $2^{\text {nd }}$ year & $13 \%(55)$ \\
\hline $3^{\text {rd }}$ year & $25.1 \%(106)$ \\
\hline $4^{\text {th }}$ year & $30.1 \%(127)$ \\
\hline $5^{\text {th }}$ year & $10.4 \%(44)$ \\
\hline Living status & \\
\hline Hostel & $13.3 \%(56)$ \\
\hline Family & $86.7 \%(366)$ \\
\hline
\end{tabular}

\begin{tabular}{|c|c|}
\hline \multicolumn{2}{|c|}{$\begin{array}{l}\text { Table 2: Sleep habits of the study participant } \\
(\mathrm{n}=422)\end{array}$} \\
\hline variables & $\% / n$ \\
\hline $\begin{array}{l}\text { Consume caffeine in any form } \\
\text { Yes } \\
\text { No }\end{array}$ & $\begin{array}{l}88.6 \%(373) \\
11.4 \%(49)\end{array}$ \\
\hline $\begin{array}{l}\text { When do you sleep during } \\
\text { college } \\
\text { nights } \\
9-11 \mathrm{pm} \\
11-1 \mathrm{am} \\
1 \mathrm{am}-3 \mathrm{am} \\
\text { After 3am }\end{array}$ & $\begin{array}{l}7.3 \%(31) \\
43.4 \%(183) \\
39.8 \%(168) \\
9.5 \%(40)\end{array}$ \\
\hline $\begin{array}{l}\text { When do you sleep during } \\
\text { Weekends? }\end{array}$ & \\
\hline $\begin{array}{l}9-11 \mathrm{pm} \\
11-1 \mathrm{am} \\
1 \mathrm{am}-3 \mathrm{am} \\
\text { After 3am }\end{array}$ & $\begin{array}{l}4.3 \%(18) \\
29.1 \%(123) \\
42.7 \%(180) \\
23.9 \%(101)\end{array}$ \\
\hline $\begin{array}{l}\text { Duration of sleep during } \\
\text { college } \\
\text { Nights? }\end{array}$ & \\
\hline $\begin{array}{l}\text { Less than 6hrs } \\
6-7 \mathrm{hrs} \\
7-8 \mathrm{hrs} \\
\text { More than } 8 \mathrm{hrs}\end{array}$ & $\begin{array}{l}46.9 \%(198) \\
38.9 \%(164) \\
12.8 \%(54) \\
1.4 \%(6)\end{array}$ \\
\hline $\begin{array}{l}\text { Daytime dysfunction due to } \\
\text { Sleepiness? } \\
\text { Never } \\
\text { Once a week } \\
\text { Twice a week } \\
\text { Thrice or More in a week }\end{array}$ & $\begin{array}{l}23.7 \%(100) \\
28.9 \%(122) \\
28.7 \%(121) \\
18.7 \%(79)\end{array}$ \\
\hline $\begin{array}{l}\text { Rate sleep quality } \\
\text { Poor } \\
\text { Average } \\
\text { Good }\end{array}$ & $\begin{array}{l}15.4 \%(65) \\
55.2 \%(233) \\
29.4 \%(124)\end{array}$ \\
\hline $\begin{array}{l}\text { Difficulty falling asleep at } \\
\text { night } \\
\text { During weekends } \\
\text { During weekdays } \\
\text { Never } \\
\text { Throughout the week }\end{array}$ & $\begin{array}{l}19.7 \%(83) \\
16.6 \%(70) \\
47.2 \%(199) \\
16.6 \%(70) \\
\end{array}$ \\
\hline $\begin{array}{l}\text { Once you have fallen asleep } \\
\text { Don't wake-up at night } \\
\text { Wake-up 1-3 Times } \\
\text { Wake-up more than } 3 \text { times }\end{array}$ & $\begin{array}{l}64 \%(270) \\
33.9 \%(143) \\
2.1 \%(9)\end{array}$ \\
\hline $\begin{array}{l}\text { Is it hard for you to stay } \\
\text { awake } \\
\text { during university hours? } \\
\text { Yes }\end{array}$ & $49.1 \%(207)$ \\
\hline
\end{tabular}




\begin{tabular}{|c|c|}
\hline caffeine $(n=422)$ & \\
\hline Variable & $\% / n$ \\
\hline $\begin{array}{l}\text { Do you exercise } \\
\text { Regularly? } \\
\text { Yes } \\
\text { No }\end{array}$ & $\begin{array}{l}26.5 \% \\
73.5 \%\end{array}$ \\
\hline $\begin{array}{l}\text { If you exercise? } \\
\text { Less than } 30 \text { mins per } \\
\text { day } \\
\text { Less than } 1 \text { hour per } \\
\text { day } \\
1-2 \text { hours per day } \\
\text { More }\end{array}$ & $\begin{array}{l}14 \%(59) \\
8.3 \%(35) \\
5 \%(21) \\
1.4 \%(6)\end{array}$ \\
\hline $\begin{array}{l}\text { Caffeine affect your } \\
\text { eating habits? } \\
\text { Increases appetite } \\
\text { Decrease appetite } \\
\text { No change } \\
\text { No caffeine intake }\end{array}$ & $\begin{array}{l}6.6 \%(28) \\
21.3 \%(90) \\
52.4 \%(221) \\
19.7 \%(83)\end{array}$ \\
\hline $\begin{array}{l}\text { What Is your total } \\
\text { screen } \\
\text { time? } \\
\text { Less than } 1 \text { hour } \\
1-2 \text { hours } \\
2-4 \text { hours } \\
\text { More than } 4 \text { hours }\end{array}$ & $\begin{array}{l}4 \%(17) \\
13.3 \%(56) \\
27.5 \%(116) \\
55.2 \%(233)\end{array}$ \\
\hline
\end{tabular}

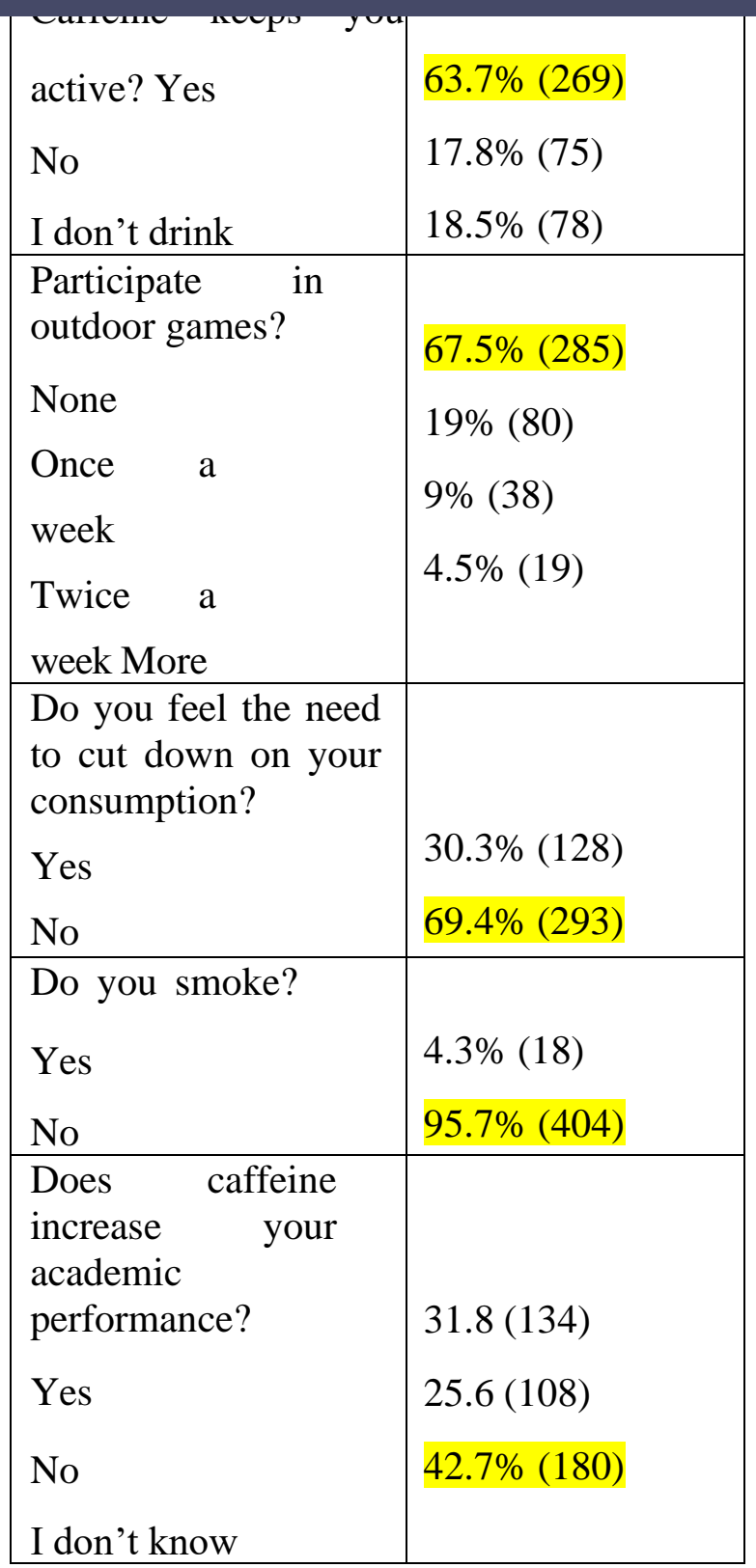


More than half $(52.4 \%)$ found no change in their appetite while $(21.3 \%)$ said caffeine decreases their appetite. Total screen time of more than half $(55.2 \%)$ of the population is more than 4 hours. Many $(63.7 \%)$ believed that caffeine keeps them active. About three fourth i.e. (73.5\%) participants do not exercise regularly, while (14\%) exercise less than 30mins per day. Major (67.5\%) number of students didn't participate in any outdoor games while another group said they participated once a week $(19.1 \%)$. Majority of the participants $(95.7 \%)$ have never smoked. One third $(30.3 \%)$ also wanted to cut down on their caffeine consumption. One third of the participants $(31.8 \%)$ reported caffeine consumption does increase their academic performance and $(57.3 \%)$ reported that it does not. Half of the participants (52.4\%) who consumed caffeine reported that it had no effect on eating habits. (Table. 3).

Majority of the participants consumed tea $61.8 \%$, followed by soft drinks $44.8 \%$, coffee $31.5 \%$, hot chocolate $17.8 \%$ and energy drink $8.1 \%$ while $7.8 \%$ reported of not using any of the beverages at all (Figure 1)

Major reason reported for the usage of the drinks was its flavor and as a habit $45 \%$, while another $40 \%$ said they regained energy by consumption. More than $1 / 3$ of the participants used it during exams $39.1 \%$ and to reduce fatigue $38.2 \%$. Less common reasons included assumption of increased academic performance $31.8 \%$, social gatherings $28.2 \%$, stress $18.7 \%$, and insufficient sleep $17.8 \%$, replace body fluids $3.6 \%$, after workout $1.7 \%$ and before training $0.9 \%$ (Figure 2)

Nearly half of the study participants responded to have moderate levels of stress $45.5 \%$ were as severe forms of stress was reported by $11.6 \%$ of the participants (Figure 3 ) 


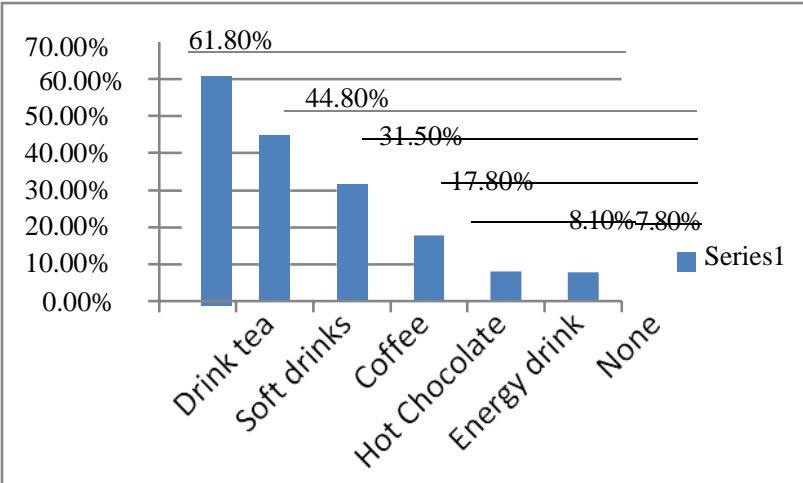


Figure 2: Reasons for consumption ( $\mathrm{n}=422)$

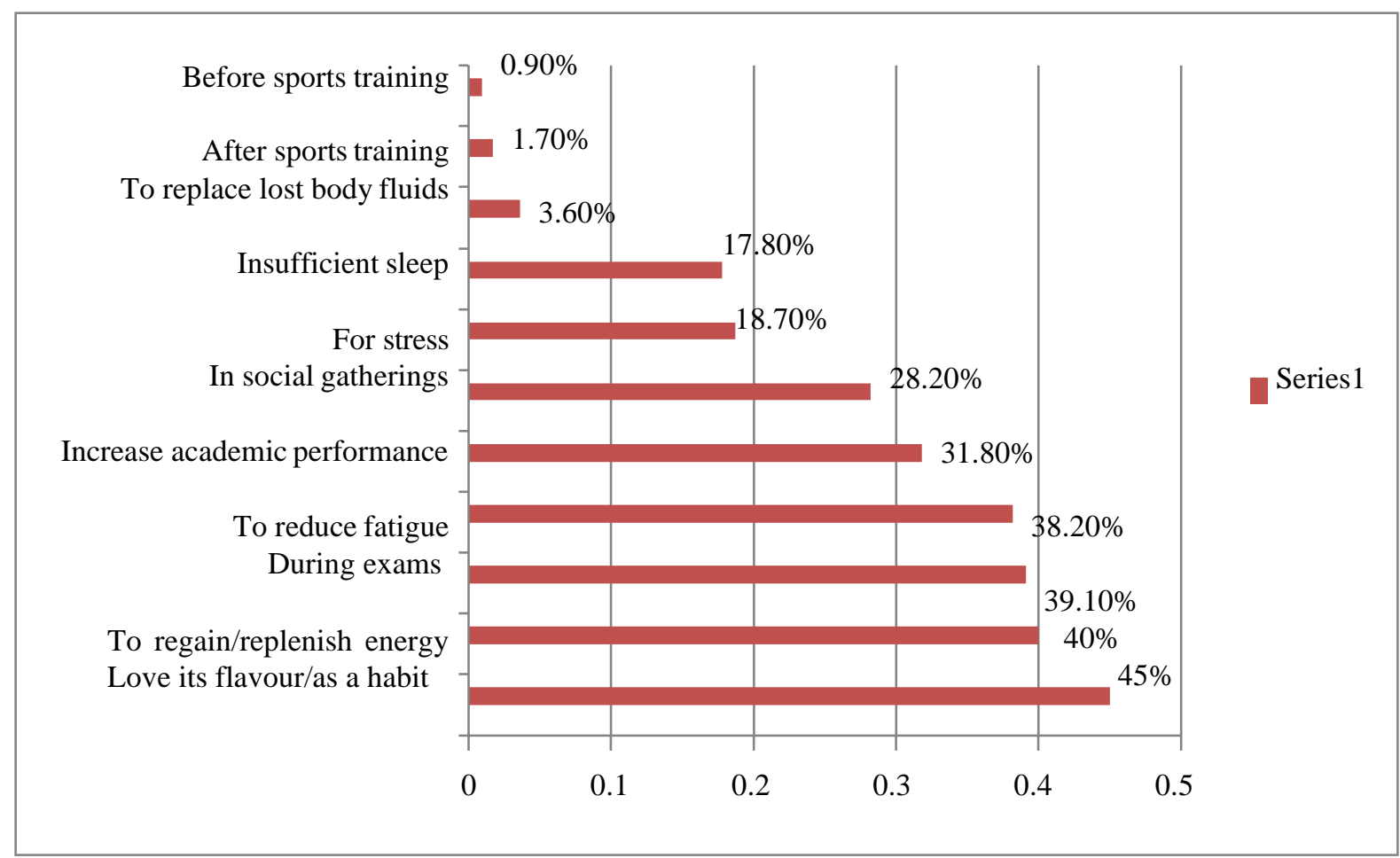

Figure 3: Levels of stress

among the study

participants $(n=422)$

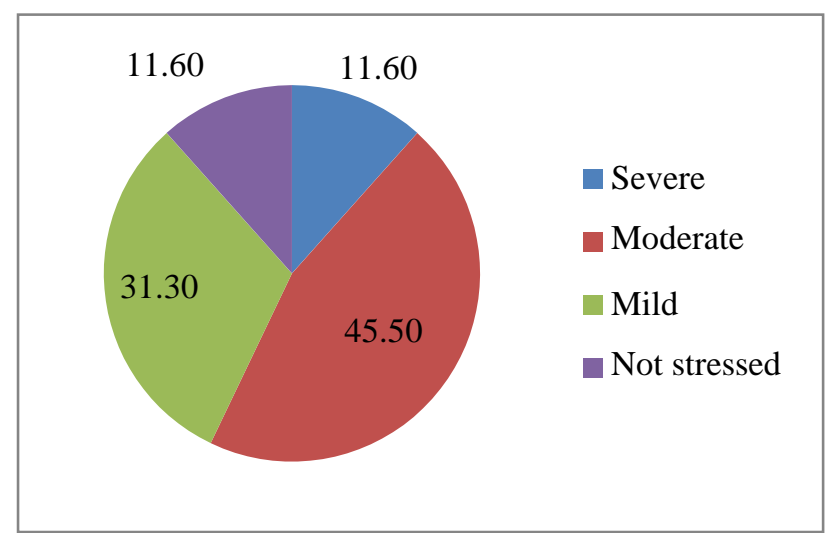




\title{
DISCUSSION:
}

Caffeine is one of the most widely consumed beverages in the world. In this study, majority of the students were reported of consuming caffeine in the form of tea $(61.6 \%)$ and coffee $(31.5 \%)$. This study demonstrated that majority of the students consuming caffeine was due to the fact that they loved its flavor/as a habit $(45 \%)$ and to replenish energy (40\%). Similar results were obtained from a study conducted in Dow University of Health Sciences, where tea was also the most popular consumed beverage ${ }^{(13)}$. However, a study conducted at King Saud University reported coffee then soft drinks as the most commonly consumed caffeinated products ${ }^{(21)}$. This study demonstrated that majority of the students had no idea of whether drinking caffeine had any impact on their academic performances 180/422 (42.7\%). Moreover, a study conducted showed that students did consider caffeine had a major role in increasing their academic performances ${ }^{(13)}$. In contrast to our study, a study from Serbia revealed that the people were mostly consuming caffeine for the reason of leisure, peer pressure and as a habit ${ }^{(22)}$.

A similar study concluded that the majority of the participants were aware of the health risks that followed caffeine usage especially effects on the heart ${ }^{(23)}$. In this study, we have concluded that mostly the students had about less than 6 hours of sleep every day 198/422 (46.9\%). Thus, our results revealed that due to the lesser duration of sleep, students suffered from day time dysfunction mostly once a week 122/422 (28.9\%) followed by twice a week $121 / 422(28.7 \%)$ in others. Similar results were obtained by a survey that concluded that, the lesser the duration of sleep the greater were the chances of daytime dysfunction ${ }^{(24)}$. A study by Jean-Louis had established a link between substance abuse and daytime sleepiness ${ }^{(24)}$. Similarly, our study claims that students had difficulty in staying awake during university hours $207 / 422$ (49.1\%) and majority of them had actually fallen asleep during class $267 / 422(63.3 \%)$. In the present survey, students were having no regular outdoor activities 285/422 (67.5\%) thus making them highly stressed. Similarly, a survey conducted stated that those students who did workout had been subjected to lesser sleep disturbances and healthier lifestyles ${ }^{(24)}$.

\section{CONCLUSION:}

This research concluded that the students who belong to private medical university consume caffeine slightly more than the students who belong to public sector medical university. This research also concluded that caffeine does have some role on sleep habits of medical students as they tend to have less sleep hours, experience day time dysfunction, average quality of sleep, and falling asleep during class. However, our research also shows that caffeine doesn't have much effect on the ability to fall asleep or on waking up during middle of the night. Regarding perception of caffeine effect on eating habits of medical students, this research has concluded that caffeine has no effect on eating habits of medical students, however, it does increase the screening time, keeps them active and smoking has no effect on caffeine intake or vice versa.

\section{CONFLICT OF INTEREST:}

The authors declare that they have NO affiliations with or involvement in any organization with any interest in the subject matter discussed in this manuscript.

\section{ACKNOWLEDGMENT:}

We are thankful to the Vice Principal, Prof. Dr. Syed Muhammad Mubeen of Hamdard College of Medicine for allowing us to collect data from the students and all the students who have participated in our research.

\section{DATA AVAILABILITY STATEMENT:}

The data that support the findings of this study are available on request from the corresponding author. The data are not publicly available due to ethical restrictions.

\section{ORCID ID OF CORRESPONDING AUTHOR:}

\author{
https://orcid.org/0000-0003-0771-0665
}




\section{REFERNECES:}

1. Sanchez SE, Martinez C, Oriol RA, Yanez D, Castañeda B, Sanchez E, Gelaye B, Williams MA. Sleep quality, sleep patterns and consumption of energy drinks and other caffeinated beverages among Peruvian college students. Health. 2013 Aug;5(8B):26.

2. Calamaro CJ, Mason TB, Ratcliffe SJ. Adolescents living the 24/7 lifestyle: effects of caffeine and technology on sleep duration and daytime functioning. Pediatrics. 2009 Jun 1;123(6):e1005-10.

3. Kline CE. The bidirectional relationship between exercise and sleep: implications for exercise adherence and sleep improvement. American journal of lifestyle medicine. 2014 Nov;8(6):375-9.

4. Lohsoonthorn V, Khidir H, Casillas G, Lertmaharit S, Tadesse MG, Pensuksan WC, Rattananupong T, Gelaye B, Williams MA. Sleep quality and sleep patterns in relation to consumption of energy drinks, caffeinated beverages, and other stimulants among Thai college students. Sleep and Breathing. 2013 Sep 1;17(3):1017-28.

5. Park SE, Kim HM, Kim DH, Kim J, Cha BS, Kim DJ. The association between sleep duration and general and abdominal obesity in Koreans: data from the Korean National Health and Nutrition Examination Survey, 2001 and 2005. Obesity. 2009 Apr;17(4):767-71

6. Dong X, Wang Y, Chen Y, Wang X, Zhu J, Wang N, Jiang Q, Fu C. Poor sleep quality and influencing factors among rural adults in Deqing, China. Sleep and Breathing. 2018 Dec 1;22(4):1213-20.

7. Surani AA, Surani A, Zahid S, Ali S, Farhan R, Surani S. To assess sleep quality among Pakistani junior physicians (House officers): A cross-sectional study. Annals of medical and health sciences research. 2015;5(5):329-33.

8. Schlarb AA, Friedrich A, Claßen M. Sleep problems in university students-an intervention. Neuropsychiatric disease and treatment. 2017;13:1989.

9. McGuire S. Institute of Medicine. 2014. Caffeine in Food and Dietary Supplements: Examining Safety_-Workshop Summary. Washington, DC: The National Academies Press, 2014.

10. Hammond D, Reid JL, Zukowski S. Adverse effects of caffeinated energy drinks among youth and young adults in Canada: a Web-based survey. CMAJ open. 2018 Jan;6(1):E19.

11. Mazanov J, Dunn M, Connor J, Fielding ML. Substance use to enhance academic performance among Australian university students. Performance Enhancement \& Health. 2013 Sep $1 ; 2(3): 110-8$. 
12. Giri PA, Baviskar MP, Phalke DB. Study of sleep habits and sleep problems among medical students of pravara institute of medical sciences loni, Western maharashtra, India. Annals of medical and health sciences research. 2013;3(1):51- 4.

13. Khan MS, Nisar N, Naqvi SA, Nawab F. Caffeine Consumption and Academic Performance among Medical Students of Dow University of Health Science (DUHS), Karachi, Pakistan. Annals of Abbasi Shaheed Hospital \& Karachi Medical \& Dental College. 2017;22(3).

14. Khademalhossini Z, Ahmadi J, Khademalhosseini Z. Prevalence of tea, coffee and nescafe consumption among high school students and its relationship with depression and anxiety. Sociology and Criminology-Open Access. 2015 Dec 8:1-6.

15. Ríos JL, Betancourt J, Pagán I, Fabián C, Cruz SY, González AM, González MJ, Rivera-Soto WT, Palacios C. Caffeinated-beverage consumption and its association with socio- demographic characteristics and selfperceived academic stress in first and second year students at the University of Puerto Rico Medical Sciences Campus (UPR-MSC). Puerto Rico health sciences journal. 2013 May $29 ; 32(2)$.

16. Richards G, Smith A. Caffeine consumption and self-assessed stress, anxiety, and depression in secondary school children. Journal of psychopharmacology. 2015 Dec;29(12):1236-47.

17. Watson E, Coates A, Kohler M, Banks S. Caffeine consumption and sleep quality in Australian adults. Nutrients. 2016;8(8):479.

18. Jefferson CD, Drake CL, Scofield HM, Myers E, McClure T, Roehrs T, Roth T. Sleep hygiene practices in a population-based sample of insomniacs. Sleep. 2005 May 1;28(5):611-5.

19. Addicott MA, Laurienti PJ. A comparison of the effects of caffeine following abstinence and normal caffeine use. Psychopharmacology. 2009 Dec 1;207(3):423-31

20. Usman A, Bhombal ST, Jawaid A, Zaki S. Energy drinks consumption practices among medical students of a Private sector University of Karachi, Pakistan. Energy. 2015 Sep

21. Al-Turki Y, Alenazy B, Algadheeb A, Alanazi M, Almarzouqi A, Alanazi A, et al. Caffeine habits among medical students in King Saud university. Int J Sci Res. 2016;5:754-64.

22. Milovanovic DD, Jakovljevic M, Scekic M, Djordjevic N. Caffeine consumption patterns and determinants among adolescents in Serbia. International journal of adolescent medicine and health. 2016;30(4).

23. Lee K, Human GP, Fourie JJ, Louw WA, Larson CO, Joubert G. Medical students' use of caffeine for 'academic purposes' and their knowledge of its benefits, side-effects and withdrawal symptoms. South African Family Practice. 2009;51(4).

24. Jean-Louis G, Von Gizycki H, Zizi F, Nunes J. Mood States and Sleepiness in College Students: Influences of Age, Sex, Habitual Sleep, and Substance Use. Perceptual and Motor Skills. 1998;87(2):507-12.

25. Pilcher JJ, Ginter DR, Sadowsky B. Sleep quality versus sleep quantity: relationships between sleep and measures of health, well-being and sleepiness in college students. Journal of 
psychosomatic research. 1997;42(6):583-96. 
